\title{
Probabilistic seismic risk evaluation of reinforced concrete buildings
}

Yeudy F. Vargas MSC

PhD student, Universidad Politécnica de Cataluña, Barcelona, Spain Alex H. Barbat PhD

Professor, Universidad Politécnica de Cataluña, Barcelona, Spain
Lluis G. Pujades PhD

Professor, Universidad Politécnica de Cataluña, Barcelona, Spain Jorge E. Hurtado PhD

Professor, Universidad Nacional de Colombia, Manizales, Colombia

The main objective of this article is to propose a simplified methodology to assess the expected seismic damage in reinforced concrete buildings from a probabilistic point of view by using Monte Carlo simulation. In order to do so, the seismic behaviour of the building was studied by using random capacity obtained by considering the mechanical properties of the materials as random variables. From the capacity curves, the damage states and fragility curves can be obtained, and curves describing the expected seismic damage to the structure as a function of a seismic hazard characteristic can be developed. The latter can be calculated using the capacity spectrum and the demand spectrum according to the methodology proposed by the Risk-UE project. In order to define the seismic demand as a random variable, a set of real accelerograms were obtained from European and Spanish databases in such a way that the mean of their elastic response spectra was similar to an elastic response spectrum selected from Eurocode 8. In order to combine the uncertainties associated with the seismic action and the mechanical properties of materials, two procedures are considered to obtain functions relating the peak ground acceleration to the maximum spectral displacements. The first method is based on a series of non-linear dynamic analyses, while the second is based on the well-known ATC-40 procedure called equal displacement approximation. After applying both procedures, the probability density functions of the maximum displacement at the roof of the building are gathered and compared. The expected structural damage is finally obtained by replacing the spectral displacement calculated using ATC-40 and the incremental dynamic procedure. In the damage functions, the results obtained from incremental static and dynamic analyses are compared and discussed from a probabilistic point of view.

\section{Notation}

$\mathrm{DS}_{i} \quad$ damage state $i$

$f_{\mathrm{c}} \quad$ concrete compressive strength

$f_{\mathrm{y}} \quad$ steel yield strength

$V \quad$ shear at base of building

$\delta \quad$ displacement at roof of building

$\mu_{x} \quad$ mean value of random variable $x$

$\rho \quad$ coefficient of variation of random variable

$\sigma_{x} \quad$ standard deviation of random variable $x$

\section{Introduction}

The vulnerability of structures subjected to earthquakes can be evaluated numerically either by using incremental static analysis or pushover analysis, or by means of non-linear dynamic analysis performed in an incremental way. All the variables involved in such structural analyses, mainly the mechanical properties and seismic actions, should be considered as random. The reason for this is that the randomness of the implied variables combined with uncertainties in the seismic hazard may lead to an underestimation or overestimation of the actual vulnerability of the structure; however, they are not always treated in this way.
Thanks to current computing capacity, a great number of structural analyses can be performed to study the behaviour of buildings from a probabilistic standpoint within the framework of a Monte Carlo simulation.

This study focuses on the non-linear seismic response of reinforced concrete (RC) buildings and on their damage analysis considering the involved uncertainties (Fragiadakis and Vamvatsikos, 2010). In pushover analysis, previous studies have considered uncertainties (Bommer and Crowley, 2006; Borzi et al., 2008; Fragiadakis and Vamvatsikos, 2010) and have evaluated the nonlinear behaviour of structures, taking into account uncertainties in the mechanical properties of materials and in non-linear static analysis (pushover) by means of the Monte Carlo method. Dolsek (2009) considered, in this type of study, seismic action as a random signal using real accelerograms, roughly compatible with design spectra, but did not take into account the uncertainties associated with the structural characteristics.

The present paper aims to assess the seismic vulnerability of a structure considering the mechanical properties of the materials 
as random variables and the seismic actions as random signals. The seismic demand for the area studied is obtained in probabilistic terms from a response spectrum chosen from Eurocode 8 (CEN, 2004). A procedure to select accelerograms, whose response spectra are compatible, in a mean sense, with the mentioned response spectrum, is then applied. In this study, the results carried out by using the above-mentioned analyses are compared by means of

- incremental static analysis or pushover analysis

non-linear dynamic analysis (NLDA) carried out in an incremental way (i.e. incremental dynamic analysis (IDA)) (Vamvatsikos and Cornel1, 2002).

Pushover analysis and NLDA have been compared in previous studies (Kim and Kuruma, 2008; Mwafy and Elnashai, 2001; Poursha et al,, 2009). Pushover analysis is used to determine the capacity curves of a structure and to obtain the expected displacement, at the roof of the building, for a given seismic area (Barbat et al., 2008; Borzi et al., 2008; Lantada et al.,

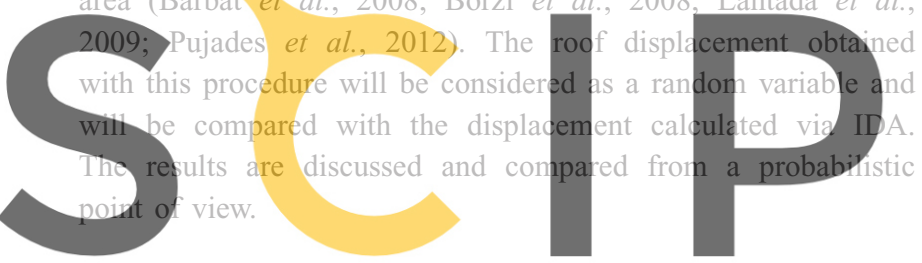

2. The studied building

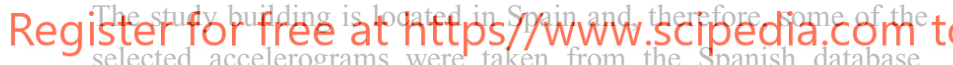

However, due to the low seismicity of the area, additional accelerograms taken from the European database were aiso used. The building is regular in plan, allowing the use of a twodimensional model. The building does not have a framed structure but one formed of columns and slabs (in this case, waffled slabs). This type of building is frequently used in Spain for family housing and for offices and has been previously studied (Vielma et al., 2009, 2010). For the purposes of this study, a simplified equivalent framed model is used, as shown in Figure 1).

The constitutive law of the structural elements is elasto-plastic without hardening or softening. In order to define the yield surfaces for the material of the columns and beams, it is necessary to create interaction diagrams between the bending moment and the axial force and between the bending moment and the angular deformation, respectively. Non-linear behaviour in shear was not considered because it was assumed that the shear capacity of the elements was adequate. Programs have been developed in Matlab in order to calculate the yielding points necessary when defining the behaviour of structural elements used in non-linear static and dynamic analyses of structures, which, in this article, are performed by means of the Ruaumoko computer software (Carr, 2000). The modified Takeda model (Otani, 1974) was chosen from among the available hysteretic models available in the Ruaumoko pro-
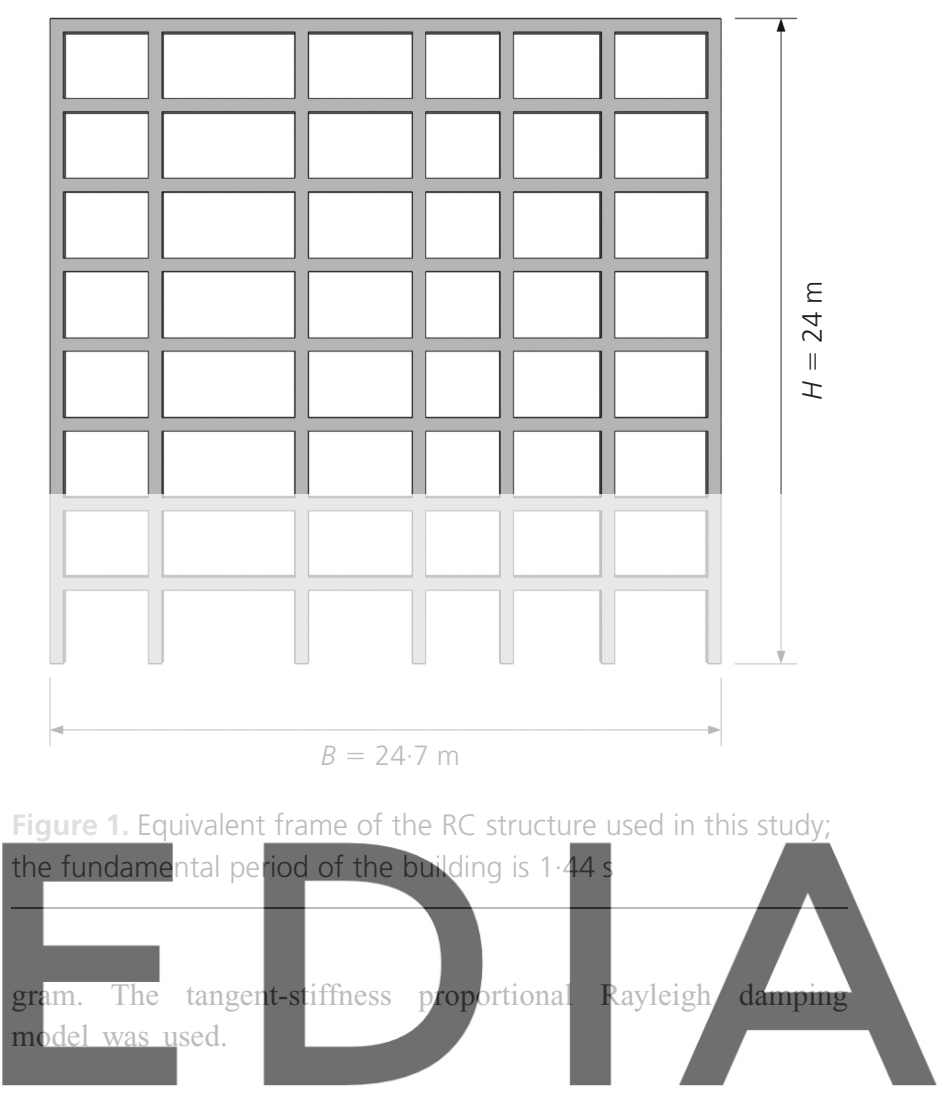

3. Incremental non-linear static analysis

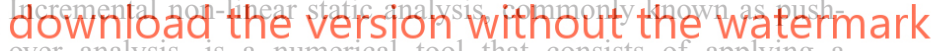 over analysis, is a numerical tool that consists of applying a} horizontal load to a structure according to a certain pattern of forces and increasing its value until structurai coliapse is reached. From this procedure, the capacity curve of the building, relating the displacement at the roof to the base shear, is obtained. It is well known that in such analysis the results change depending on the variation of load pattern with height. Furthermore, it is very difficult to establish the extent to which the load should be increased in order to reach building collapse. Moreover, a load maintaining the pattern corresponding to the first mode of vibration of the elastic structure cannot capture the effect of higher modes. To overcome these difficulties, the so-called adaptive pushover method proposed by Satyarno (1999) was used; it is referred to here simply as pushover analysis. Loading patterns are recalculated at each step based on the deformed shape of the structure. The collapse limit is reached when the fundamental frequency calculated for the tangent-stiffness matrix tends to zero. Figure 2 shows a comparison of different capacity curves calculated for different load patterns for the studied structure. The collapse limits for the rest of the load patterns in Figure 2(a) (i.e. rectangular, triangular and first mode) correspond to a total drift of $1 \cdot 5 \%$ of structural height.

As already mentioned, the mechanical properties of the materials (e.g. concrete compressive strength, $f_{\mathrm{c}}$, and reinforced yield strength, $f_{\mathrm{y}}$ ) are random variables. The distribution assumed for these variables is Gaussian; the parameters that define these 


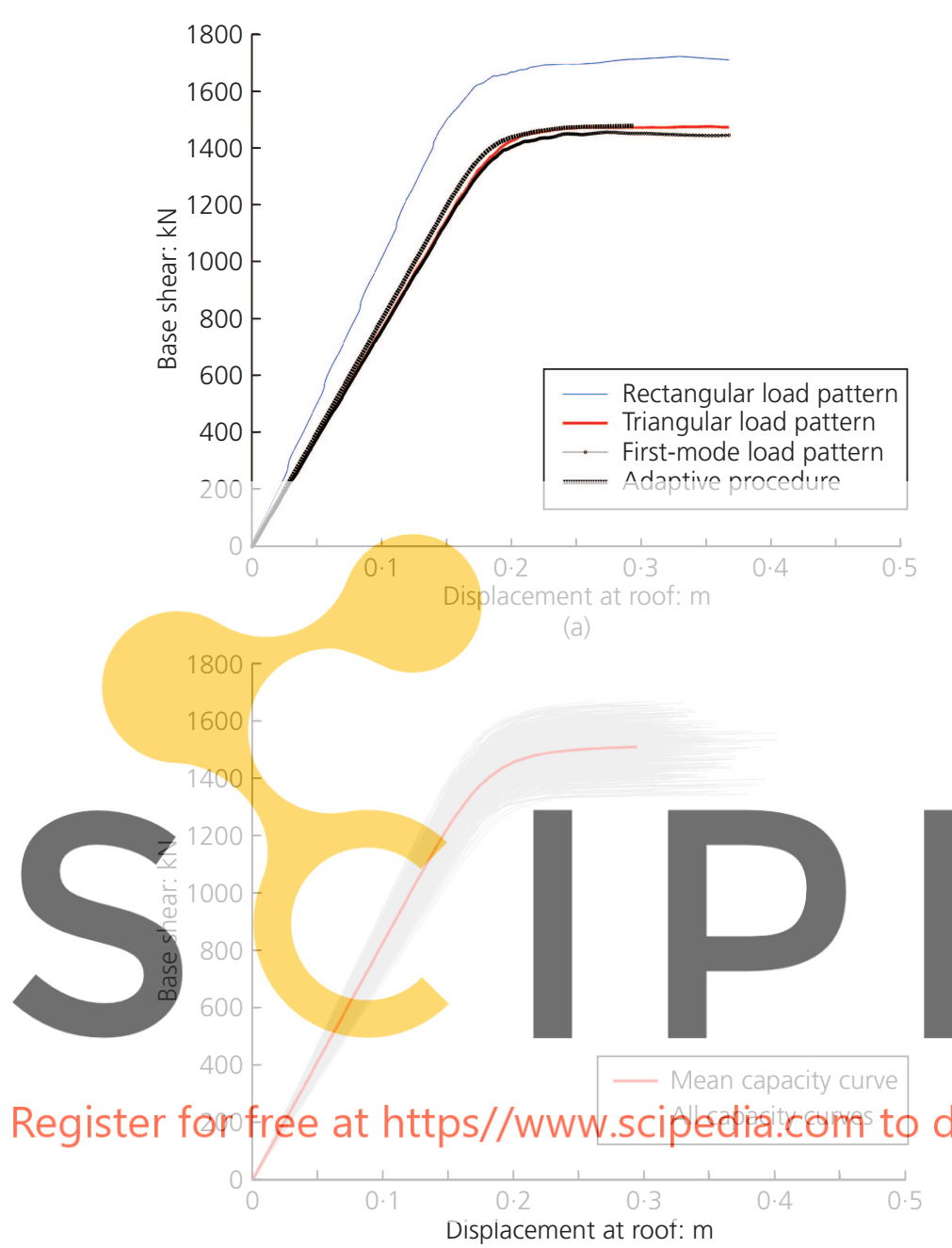

(b)

Figure 2. Capacity curves obtained with different load patterns (a) and via Monte Carlo simulation (b)

distributions, the mean value, $\mu$, and the standard deviation, $\sigma$, as well as the coefficient of variation, $\rho$, are shown in Table 1. Other possible uncertainties, such as those related to the placement of reinforcing bars, variations in section dimension, strain hardening and ultimate strength of steel, to name just a few, can also be included in the probabilistic structural analysis, but only the uncertainties included in Table 1 are considered in this article.

It is well known that spatial variability between the mechanical

\begin{tabular}{lrrr}
\hline & \multicolumn{1}{c}{$\mu$} & \multicolumn{1}{c}{$\sigma$} & $\rho: \%$ \\
\hline$f_{\mathrm{c}}$ & 30000 & 4500 & $15 \cdot 0$ \\
$f_{\mathrm{y}}$ & 420000 & 31500 & $7 \cdot 5$
\end{tabular}

Table 1. Characteristics of the probability distribution of the mechanical properties of the structural elements characteristics of the structural elements greatly influences the results (Franchin et al., 2010). This variability is considered in this work by generating one random sample for the compressive strength of concrete $\left(f_{\mathrm{c}}\right)$ for all the columns of the same storey of the building. This is based on the fact that, usually, the concrete for the structural elements of one particular storey comes from one pour. Even if the properties of the reinforcement can be supposed independent from rebar to rebar, only one random sample of the tensile strength of the steel $\left(f_{\mathrm{y}}\right)$ was generated for each column of the same storey. The same criterion was used to generate random samples for the characteristics of the materials of beams of the same storey. It is important to note that the samples corresponding to the different storeys are independent (i.e. correlation between properties at each floor was not considered).

After generating 1000 samples of mechanical properties $f_{\mathrm{c}}$ and $f_{\mathrm{y}}$ using the Latin hypercube method, 1000 capacity curves were obtained. They are plotted in Figure 2(b), which shows the uncertainties in the results

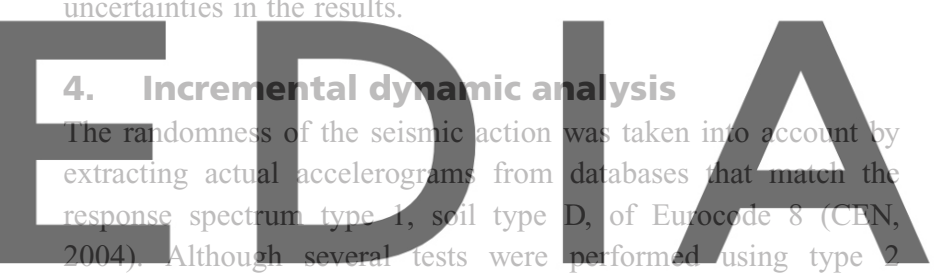

spectra, the type 1 spectrum for soil D is used in this article in downtoadnifhe version without the waternark (for type 2 spectra, the accelerograms needed to be scaled for peak ground accelerations (PGAs) higher than those expected in Spain). Twenty acceleration records were selected whose mean $5 \%$ damped elastic response spectrum was in the range of $\pm 5 \%$ of the code spectrum. Several methods can be used to select the accelerograms that describe the seismic hazard of an area (Hancock et al., 2008). This study used a procedure based on least squares that consists of selecting a group of accelerograms whose mean spectrum minimises the error while respecting the target spectrum (Vargas et al., 2013). Figure 3 shows the Eurocode 8 spectrum and the mean spectrum of the 20 selected accelerograms.

The selected accelerograms were scaled to different levels of PGA and then used to perform a series of NLDA within the framework of the IDA. The scaling method used consists of incrementing the acceleration ordinates by a scalar, allowing definition of the desired PGA levels. Even if, in this way, the initial frequency content of the seismic action is maintained, this scaling method is adequate for the purpose of this article (i.e. comparison, in a probabilistic way, of the results obtained with static and dynamic non-linear analysis methods considering uncertainties).

The IDA was performed by combining the uncertainties in the mechanical properties of the building with those involved in the seismic action. The objective was to obtain the evolution of 

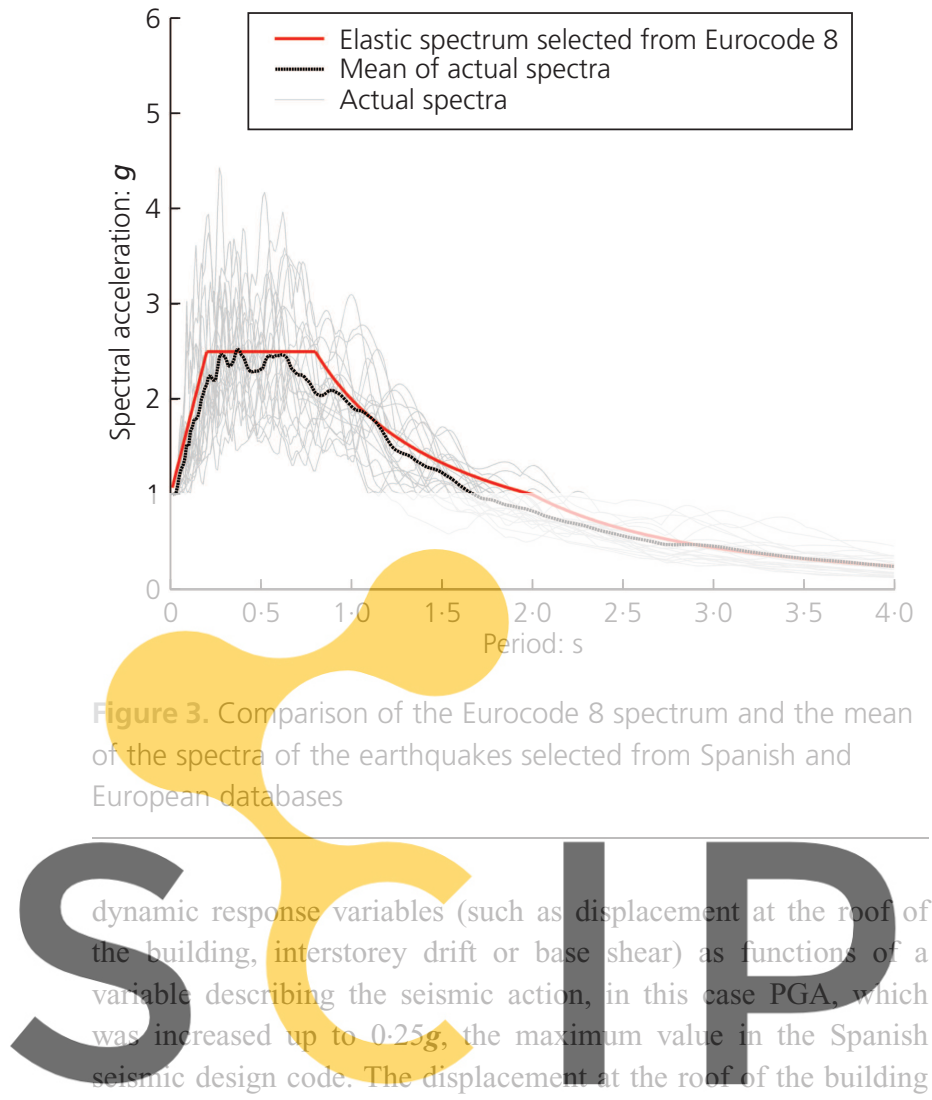

and the base shear, obtained by performing NLDA, are random

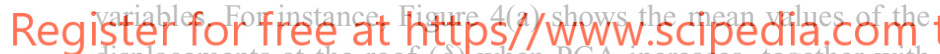
displacements at the roof ( $\delta$ ) when PGA increases, together with \pm 1.65 standard deviation intervals (i.e. 95\% confidence levels). Figure 4(b) shows the evolution of the standard deviation of $\delta$, $\sigma_{\delta, \mathrm{mp}+\mathrm{sa}}$, which involves the uncertainties in the mechanical properties of the materials (mp) and in the seismic action (sa). New simulations were performed to evaluate the contribution of the above-mentioned uncertainties to the total standard deviation. The contribution of the uncertainties related to the mechanical properties, $\sigma_{\delta \text {, mp }}$, was established by considering a mean seismic action whose response spectrum is again Eurocode 8 type 1, soil D. A synthetic accelerogram matching this spectrum was generated and used in a series of NLDA performed with random mechanical properties of the materials. The contribution of the uncertainties related to the seismic action, $\sigma_{\delta \text {, sa }}$, was calculated using an analogous procedure but, in this case, the mechanical properties are those related to the mean values, and the seismic action is described by the accelerograms corresponding to the 20 spectra of Figure 3. The obtained standard deviations, $\sigma_{\delta, \mathrm{mp}}$, $\sigma_{\delta \text {, sa }}$ and $\sigma_{\delta, \mathrm{mp}+\mathrm{sa}}$, are shown in Figure 5(a), which suggests that the uncertainties of the mechanical properties could be neglected because their contribution to the total uncertainty is small.

The evolution of the standard deviation of the base shear, $\sigma_{V \text {, mp+sa }}$, was also analysed, again separating the contribution of each source of uncertainty $\left(\sigma_{V, \mathrm{mp}}\right.$ and $\left.\sigma_{V \text {, sa }}\right)$. Figure $5(\mathrm{~b})$ shows that, for PGA $>0 \cdot 1 \boldsymbol{g}, \sigma_{V \text {, mp }}$ increases while $\sigma_{V \text {, sa }}$ decreases. Starting from a PGA $>0 \cdot 15 \boldsymbol{g}, \sigma_{V, \mathrm{mp}+\mathrm{sa}}$ is governed by $\sigma_{V, \mathrm{mp}}$.
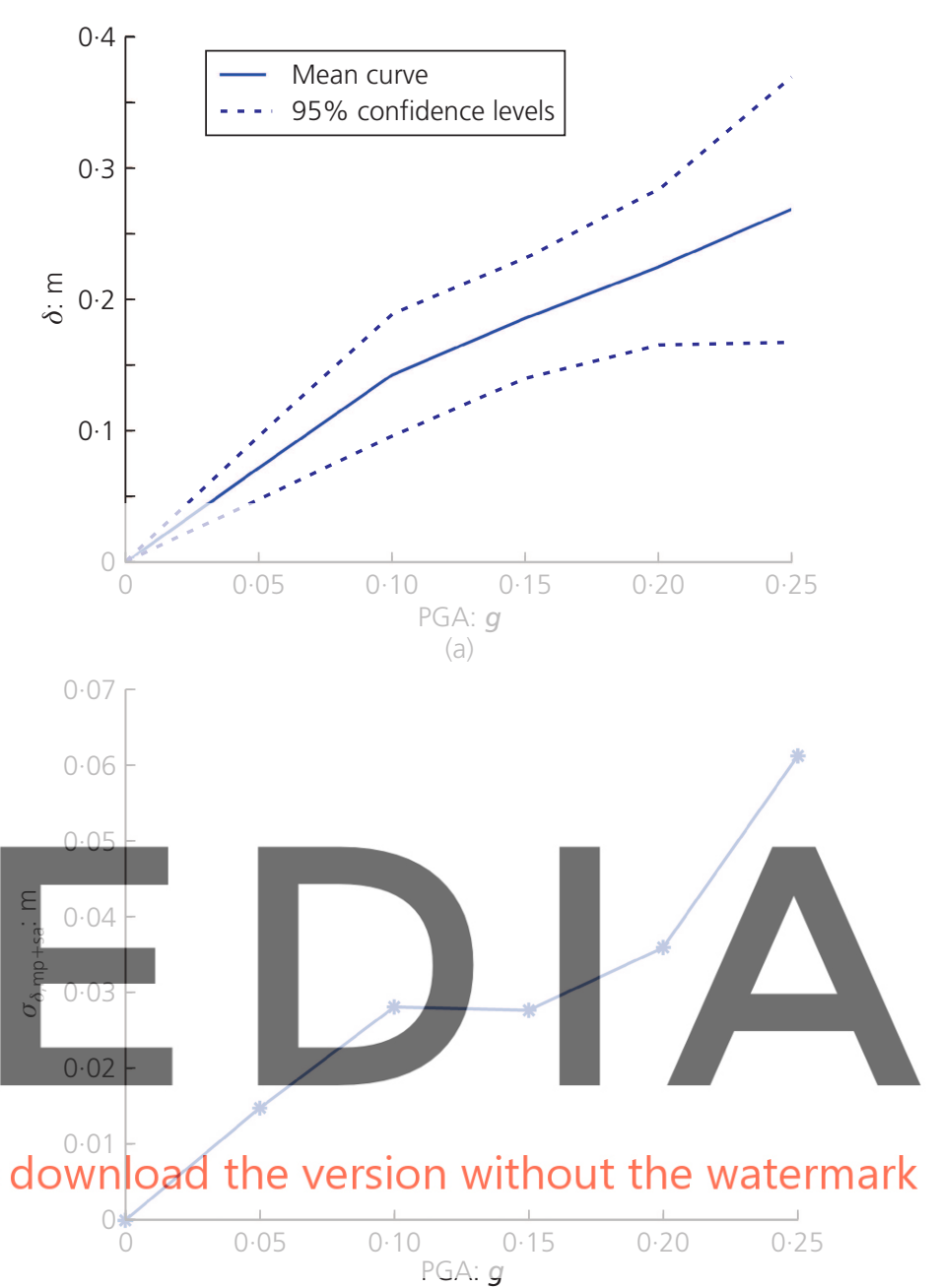

(b)

Figure 4. (a) Relationship between PGA and displacement at the roof $\delta$. (b) Relationship between PGA and standard deviation of displacement at the roof $\sigma_{\delta, \mathrm{mp}+\mathrm{sa}}$

For this reason, when the structure is damaged (in this case for PGA $>0 \cdot 1 \mathrm{~g}$ ), the influence of the uncertainties related to the mechanical properties should be taken into account. Figures 5(a) and 5(b) also show the quadratic combination of the individual standard deviations of $\delta$ and $V$, which are very similar to $\sigma_{\delta \text {, mp }+ \text { sa }}$ and $\sigma_{V, \mathrm{mp}+\mathrm{sa}}$, respectively. This is because the random variables related to the mechanical properties and to the seismic action are independent.

\section{Capacity spectrum, damage states and fragility curves}

\subsection{Capacity spectrum and bilinear representation}

Once the capacity curve of the structure has been calculated, it is useful to transform it into the capacity spectrum by means of the procedure proposed in ATC-40 (ATC, 1996). The capacity spectrum is represented in spectral acceleration-spectral displacement coordinates and is often used in its simplified bilinear 


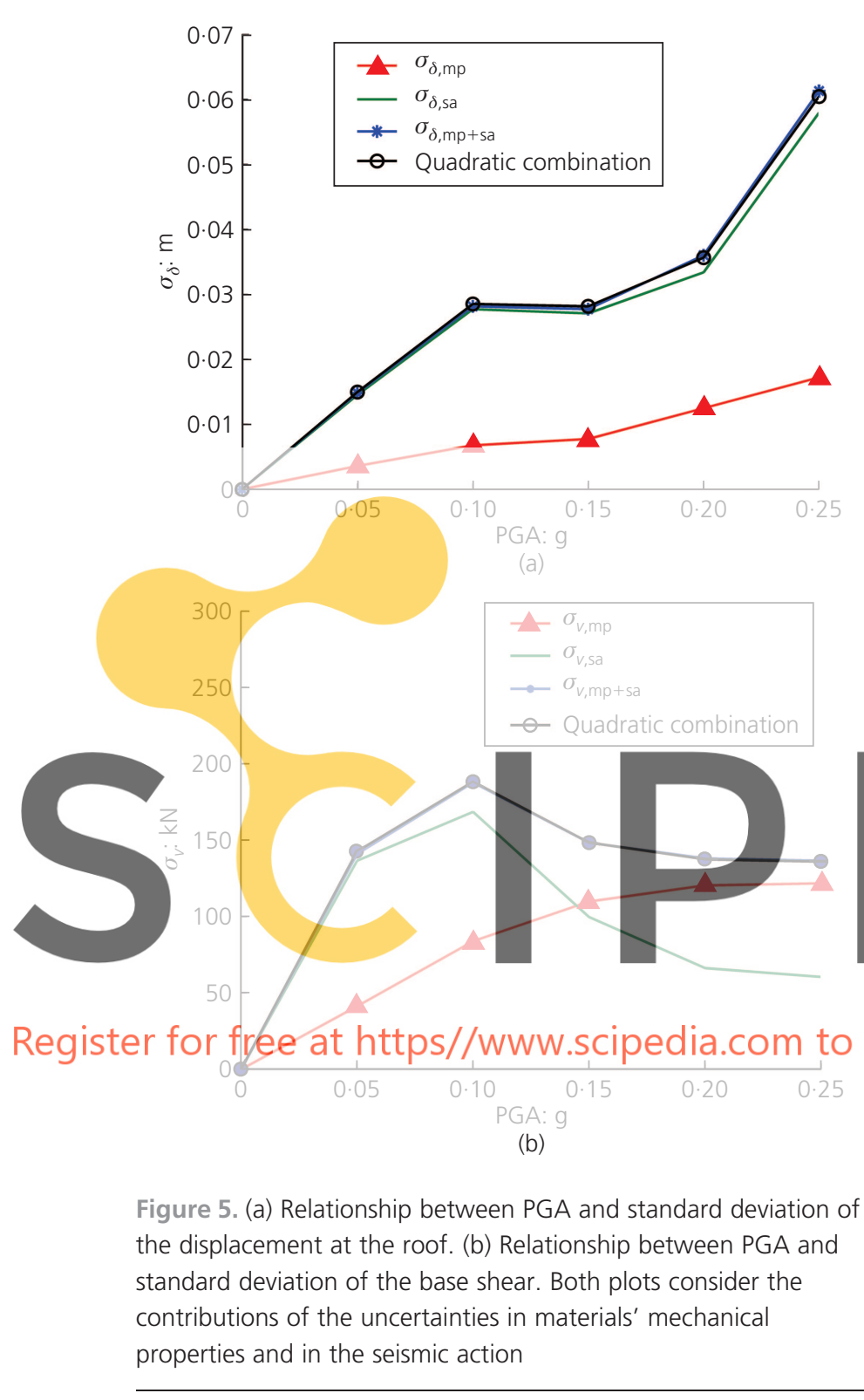

form, defined by the yielding point $\left(D_{\mathrm{y}}, A_{\mathrm{y}}\right)$ and ultimate capacity point $\left(D_{\mathrm{u}}, A_{\mathrm{u}}\right)$, as shown in Figure 6(a).

\subsection{Damage states}

In order to analyse the expected damage, simplified methods are used to obtain the damage state (DS) thresholds and the corresponding fragility curves. Four non-null DSs are considered
- $\mathrm{DS}_{1}$ : slight
- $\mathrm{DS}_{2}$ : moderate
- $\mathrm{DS}_{3}$ : severe
- $\mathrm{DS}_{4}$ : extensive to collapse

For a given DS, according to the hypothesis considered in the Risk-UE project (Milutinovic and Trendafiloski, 2003), the DS threshold is defined by the $50 \%$ probability of occurrence. This
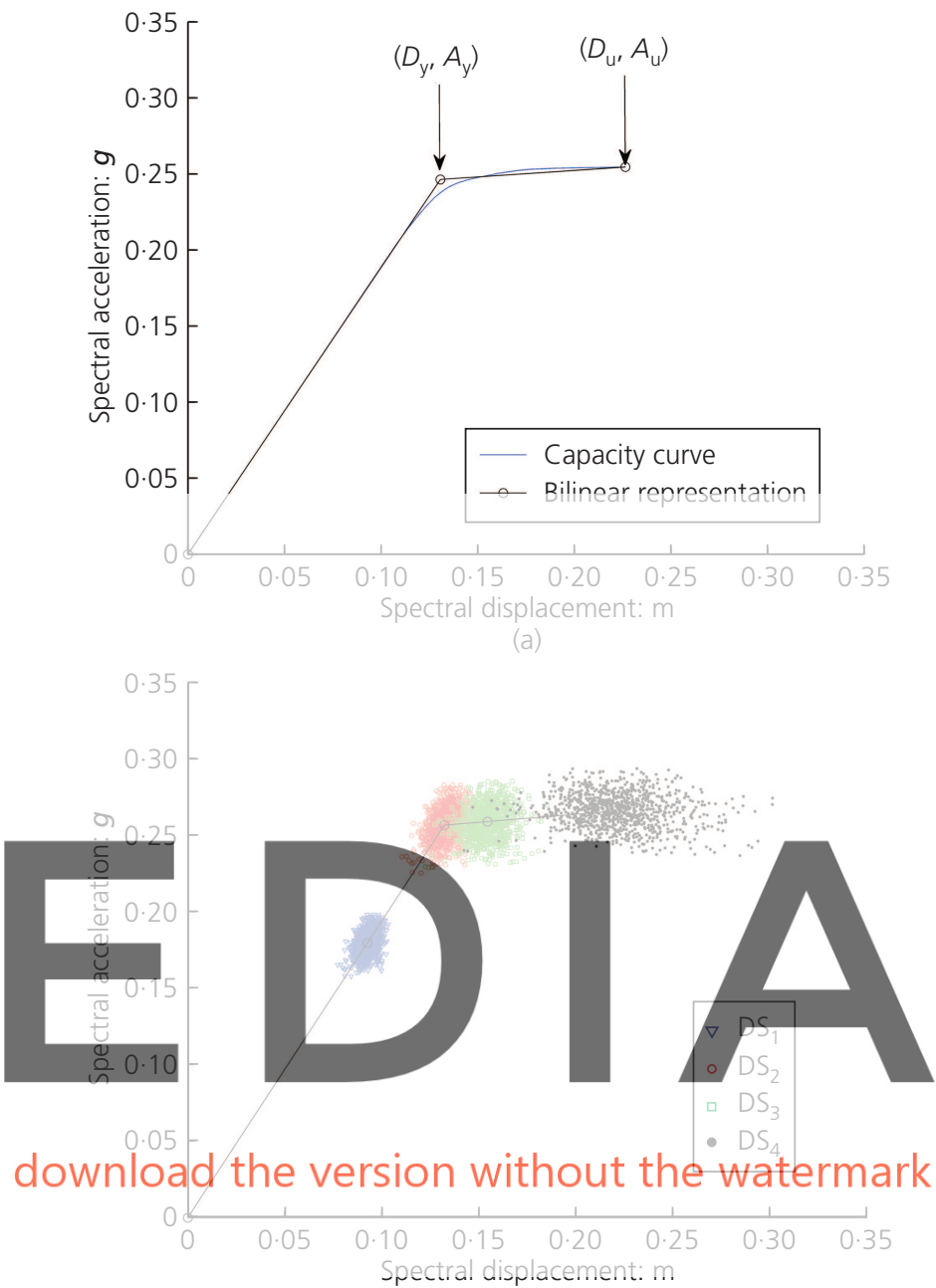

(b)

Figure 6. (a) One of the capacity spectra of the studied building and its bilinear representation. (b) Damage states as random variables

DS threshold can be defined in the following simplified way from the bilinear capacity spectrum (Barbat et al., 2010, 2011; Lantada et al., 2008)

$$
\begin{aligned}
& \mathrm{DS}_{1}=0 \cdot 7 D_{\mathrm{y}} \\
& \mathrm{DS}_{2}=D_{\mathrm{y}} \\
& \mathrm{DS}_{3}=\mathrm{DS}_{2}+0 \cdot 25\left(D_{\mathrm{u}}-D_{\mathrm{y}}\right)
\end{aligned}
$$

1. $\mathrm{DS}_{4}=D_{\mathrm{u}}$

The DS thresholds were established for all the capacity spectra calculated for the structure under study. Thus, considering the DS thresholds as random variables, Figure 6(b) shows the results obtained and the mean values for each DS. The figure also illustrates how the dispersion increases as DSs increase. This fact 
indicates that, when the structure is in non-linear behaviour, uncertainties at a certain damage level increase. The mean and standard deviation of each DS are shown in Table 2.

Due to the fact that the DSs are random, the variables derived from them are also random. For instance, the ductility capacity of the building is obtained as a random variable, and its histogram is

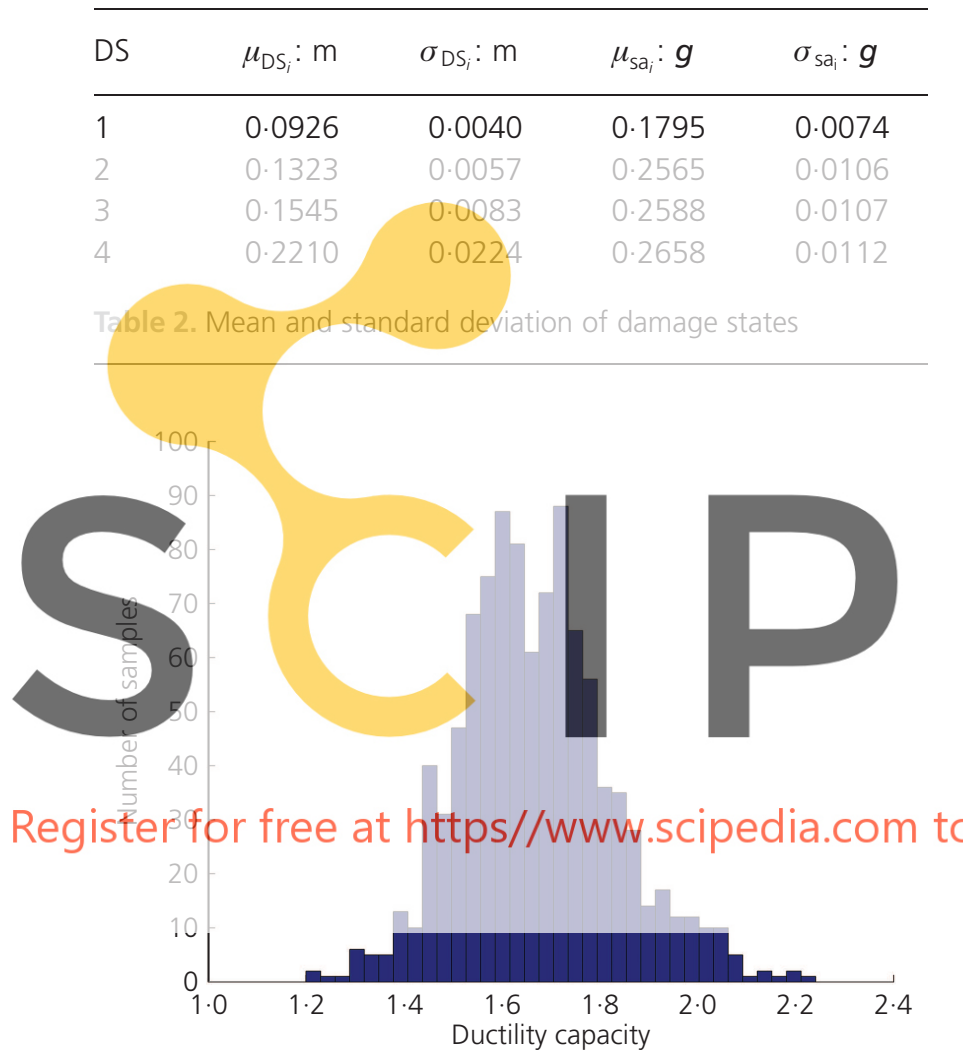

(a)

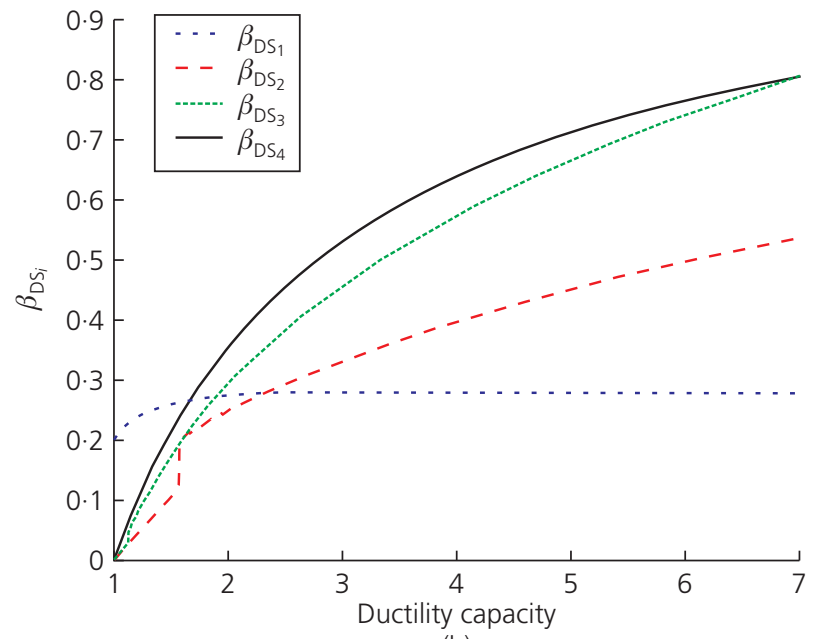

(b)

Figure 7. (a) Ductility capacity of the building under study when mechanical properties are random. (b) Correlation between ductility capacity and variables $\beta_{\mathrm{DS} 1}-\beta_{\mathrm{DS} 4}$ represented in Figure 7(a). The figure shows how the calculated mean value of 1.7 is consistent with, but lower than, the behaviour factor of $2 \cdot 0$ required by the Spanish code NCSE-02.

For each DS threshold, the corresponding fragility curve is defined by the probability of exceeding the corresponding threshold as a function (in our case) of the spectral displacement. It is assumed that the fragility curves follow a standard log-normal cumulative distribution function. Each fragility curve is then obtained using

2. $P\left(\mathrm{DS}_{i} / \mathrm{SD}\right)=\phi\left[\frac{1}{\beta_{\mathrm{DS}_{i}}} \ln \left(\frac{\mathrm{SD}}{\overline{\mathrm{SDDS}_{i}}}\right)\right]$

where $\mathrm{SD}$ is the spectral displacement and $\overline{\mathrm{SD}_{\mathrm{DS}_{i}}}$ is the mean value of the log-normal distribution, which is the corresponding DS threshold as defined above. $\beta_{\mathrm{DS}_{i}}$ is the standard deviation of the natural logarithm of the spectral displacement of $\mathrm{DS}_{i}$. In Equation 2, $\overline{\mathrm{SD}_{\mathrm{DS}}}$ can be determined from the capacity spectrum and $\beta_{\mathrm{DS}}$ can be estimated by asstuming that the damage follows
binomial distribution and, finaly, by using a mean squates
procedure to fit the fragility curves (see Lantada et al., 2008).
Notwithstanding, there is a correlation between the ductitity
capacity of the building and the $\beta_{\mathrm{DS}_{i}}$ variables of exch fragility
curve, which was bund by relating the rults ob ained to the Monte Carlo method. This correlation is very useful because one

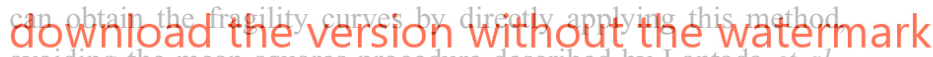
avoiding the mean squares procedure described by Lantada et al., 2008 and thus reducing the calculation time considerably. Figure 7 (b) shows this correlation.

Figure 8(a) shows the 1000 fragility curves obtained for all the calculated capacity spectra applying the simplified method described above. Obviously, according to Figure 6(b), as the considered DS increases, so do the uncertainties involved in the corresponding fragility curve. It should be mentioned that the collapse probability obtained with pushover analysis could be underestimated due to the impossibility of considering the effect of cyclic degradation, which is included in the dynamic calculation.

The probabilistic pushover analysis shows that the calculated capacity curves have features that exhibit a random distribution (elastic stiffness and ductility capacity, among others). These random distributions can be related to the DS thresholds. For example, Figure 8 (b) shows the results of a sensitivity test on the influence of the mechanical properties of the materials and the DS thresholds; elastic stiffness is used as an independent variable in this test. Damage states $\mathrm{DS}_{1}$ and $\mathrm{DS}_{2}$ are practically independent of stiffness while, for $\mathrm{DS}_{3}$ and $\mathrm{DS}_{4}$, the spectral displacement decreases with increasing stiffness, indicating that the probability of the corresponding DS increases with stiffness.

Figure 9(a) shows the mean fragility curves and Figure 9(b) shows the corresponding standard deviations as functions of the 


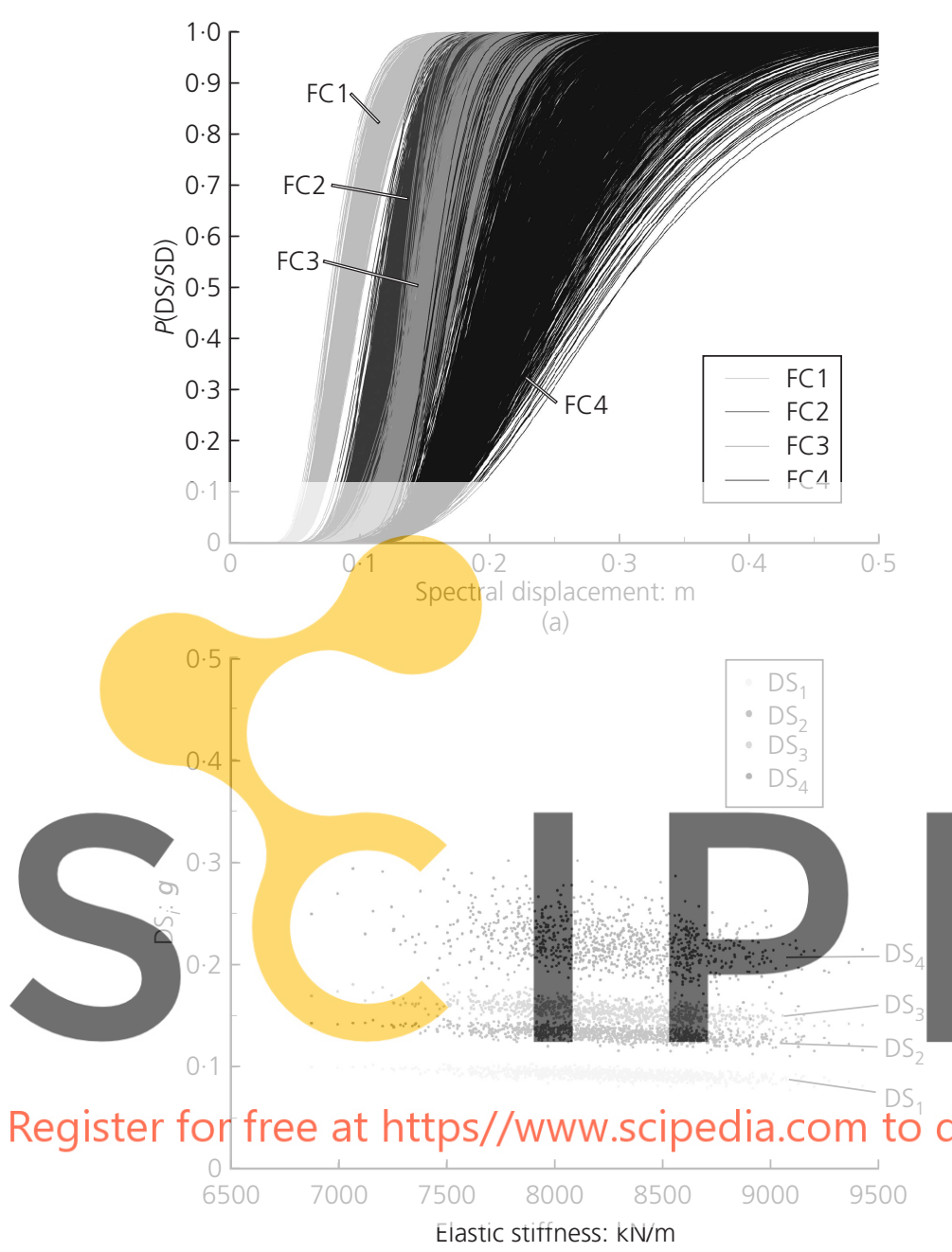

(b)

Figure 8. (a) Fragility curves (FCs) as random variables. (b) Sensitivity test for DS and initial stiffness

spectral displacement. These figures clearly depict the dependence of uncertainties on damage states. For instance, the coefficient of variation of $\mathrm{DS}_{4}$ may be greater than $10 \%$, which means that, for a confidence level of $95 \%$, the increase in the probability of failure will be greater than $16 \cdot 5 \%$. This increase confirms the importance of analysing the problem from a probabilistic point of view.

\section{Expected spectral displacement and damage index}

The maximum expected displacement in a building due to the seismic hazard of the area was obtained in Section 4 using NLDA; the results are presented in Figures 4 and 5. Different studies have searched for simplified procedures to estimate the expected displacement (Kim and Kuruma, 2008). A much simpler procedure is the so-called equal displacement approximation (EDA), which is described in ATC-40 (ATC, 1996) (see also
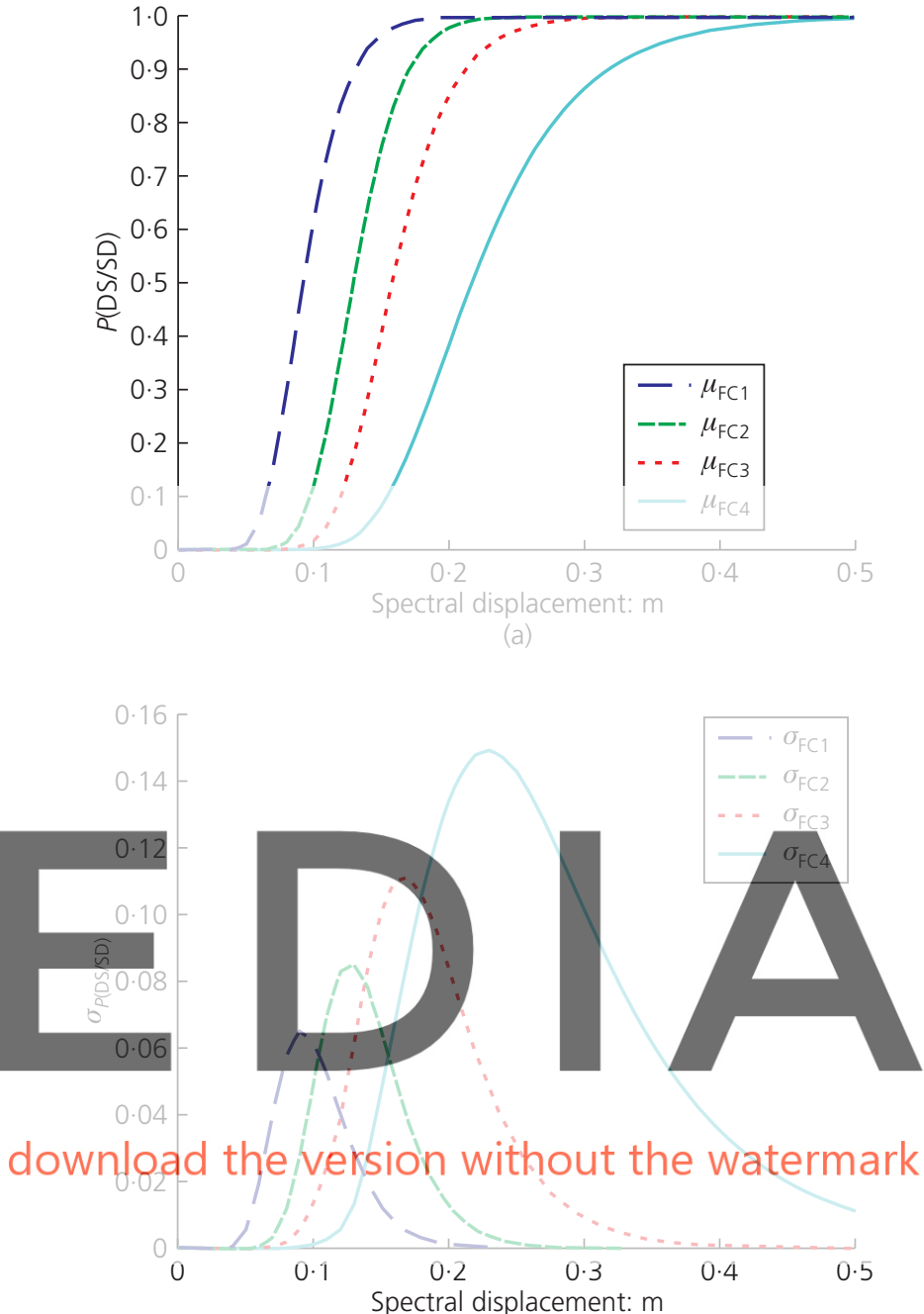

(b)

Figure 9. (a) Mean fragility curves obtained via Monte Carlo simulation. (b) Standard deviation of the fragility curves

Mahaney et al., 1993). The EDA is performed by using the spectra corresponding to selected accelerograms in order to perform a better comparison with the results obtained from the NLDA. Due to the fact that the EDA is a linear procedure, it is sufficient to scale the spectra for a single PGA. In order to express the expected spectral displacement (ESD) as a function of the PGA, spectra are scaled to $0 \cdot 25 \mathrm{~g}$ to obtain the mean and standard deviation. Figure 10 shows the EDA procedure considering the uncertainties associated with both seismic action and the materials' mechanical properties.

The mean ESD and its standard deviation obtained using the EDA are shown in Figures 11(a) and 11(b), respectively, where the NLDA results are also given. The main conclusion of this analysis is that the EDA methodology provides an adequate approximation for the ESD of the building because it does not underestimate the expected displacement. 

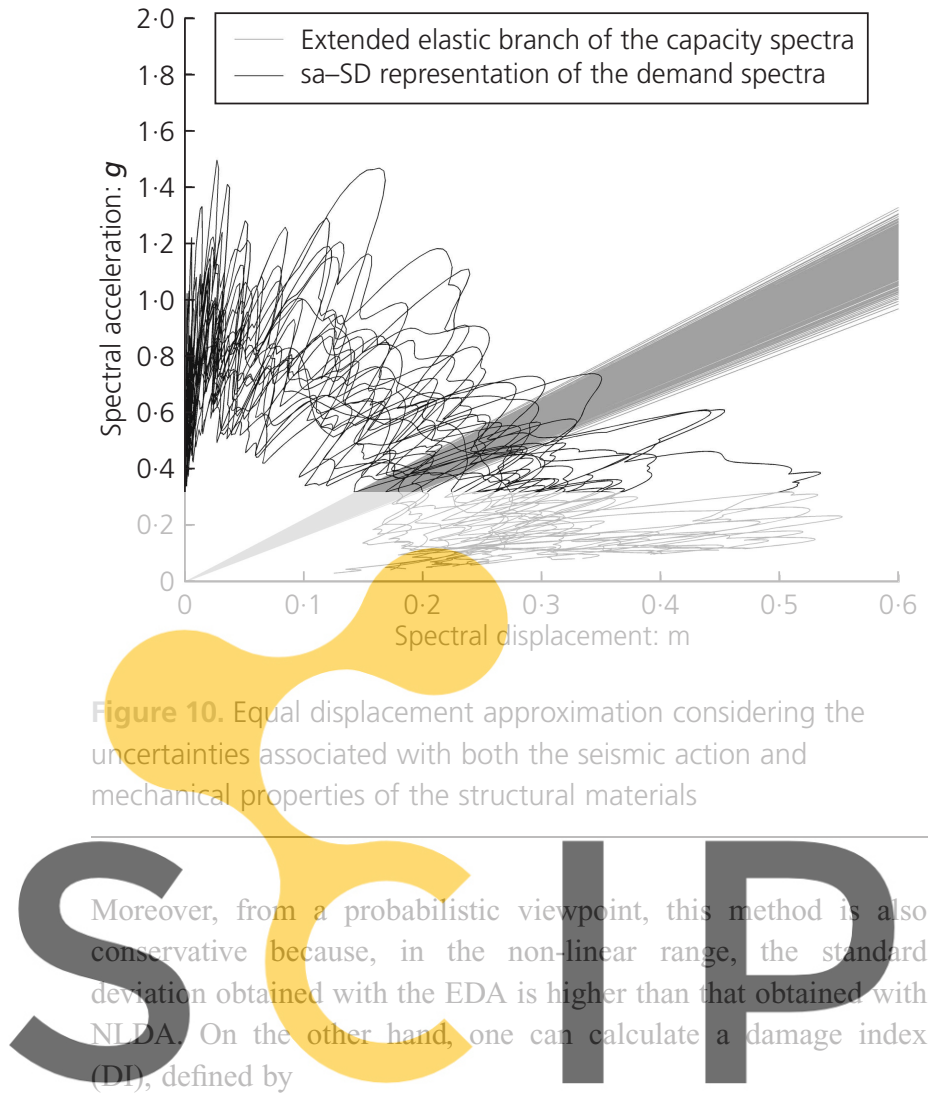

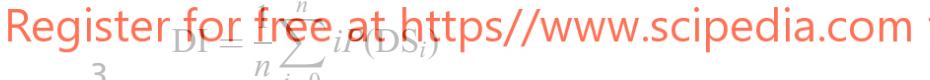

where $n$ is the number of non-null DSs ( $n=4$ in this case) and $P\left(\mathrm{DS}_{i}\right)$ is the probability of damage state $i$, which can be easily calculated from the fragility curves. The DI is the normalised mean damage grade, which is a measure of the overall damage in the structure (Barbat et al., 2008). The authors proposed Equation 3 to calculate the overall damage, taking into account that the higher DSs have more influence on the global damage state DI of the structure and also that this equation provides the main parameter of the binomial distribution, which allows one to obtain the fragility curves in a simpler manner. The values of the coefficients that multiply the four probabilities of the DSs $(0 \cdot 25$, $0.5,0.75,1.0)$ can be calibrated in order to improve the DI in Equation 3, should observed damage values be available. The DI can also be plotted as a function of the ESD. Thus, it can be calculated for any spectral displacement but, in order to include the randomness associated with seismic action, a comparison between the DIs obtained with EDA and with NLDA requires computing the PGA corresponding to each spectral displacement by using the relation shown in Figure 11(a).

Figure 12 shows the obtained results, namely the mean values and the $95 \%$ confidence level curves. Again, the results confirm that the EDA is conservative with respect to NLDA, even when considering
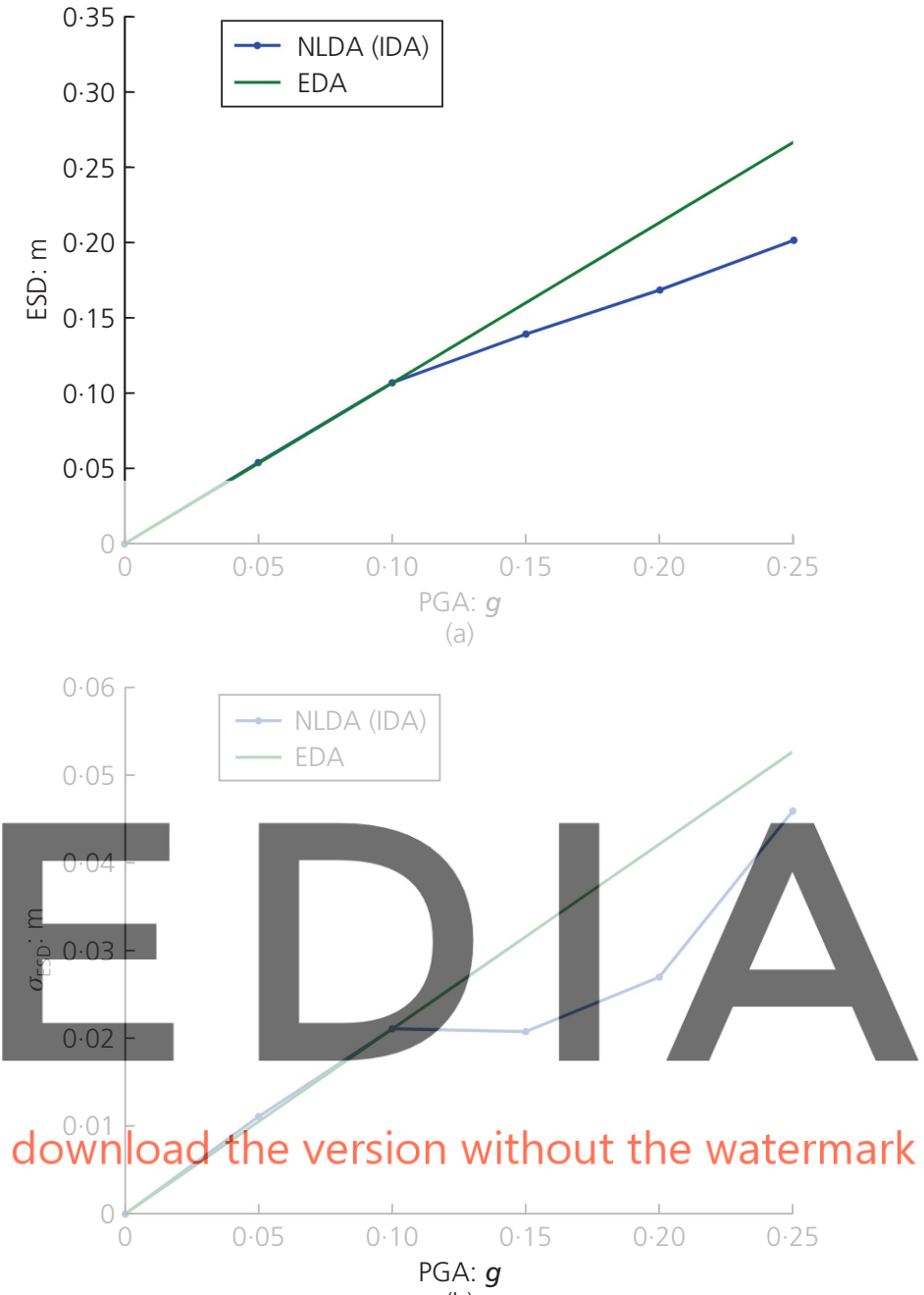

(b)

Figure 11. (a) Comparison of relationship of PGA to the ESD obtained using EDA and NLDA. (b) Comparison of relationship of PGA to standard deviation of the ESD obtained by means of EDA and NLDA

a confidence level of $95 \%$ for random variables. However, should the variables not be treated using a probabilistic approach, this would result in an underestimation of the actual damage that may occur in the building. In the case of the building analysed in this article, the DI estimated using a deterministic approach is $25 \%$ of that computed from a probabilistic point of view.

\section{Discussion and conclusion}

This article has assessed the vulnerability, fragility and expected damage of a RC building. However, the results obtained go further as they compare, in a probabilistic way, non-linear static and dynamic analysis procedures. The problem is faced from a probabilistic point of view, since uncertainties in the parameters are considered with regard to the mechanical properties of the materials and seismic demands. Despite the fact that IDA is a powerful tool to assess the structural behaviour of buildings under 


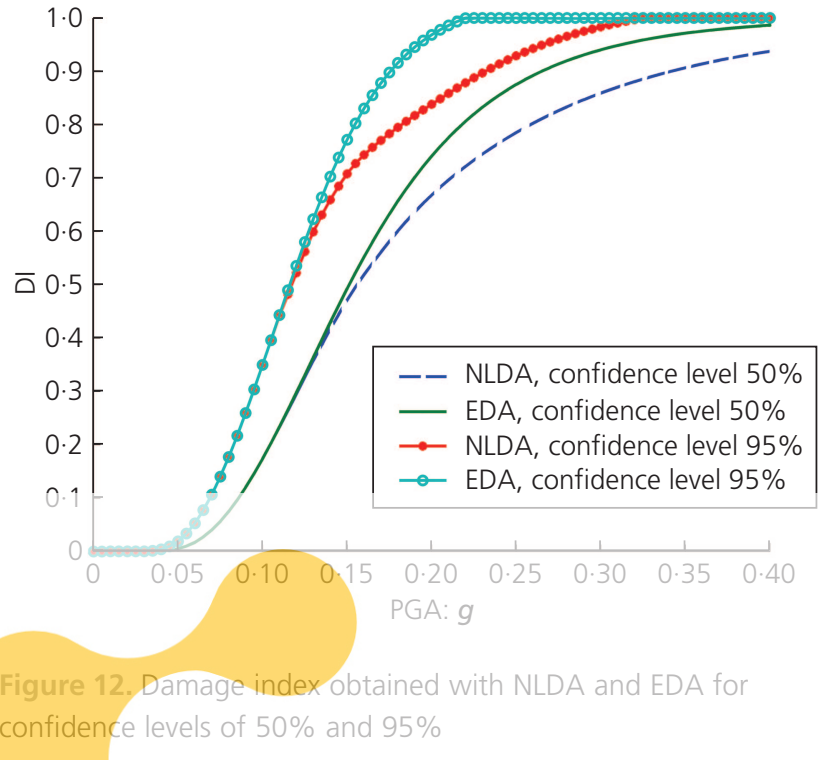

confidence levels of $50 \%$ and $95 \%$

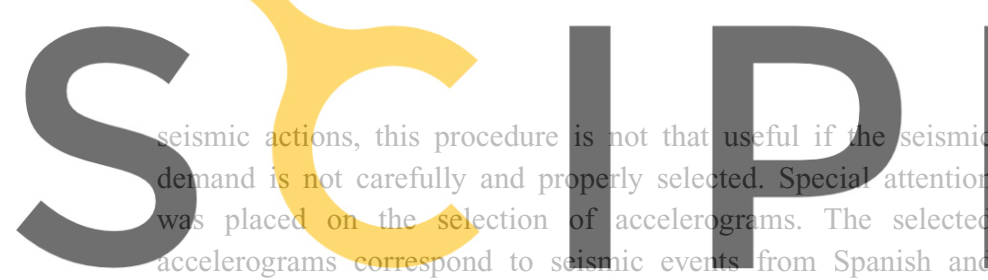

European strong motion records databases. In order to reach a

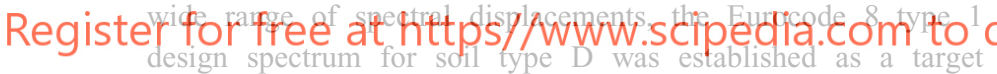

demand. The accelerograms were selected according to this

criterion and scaled to cover PGA values up to $0 \cdot 25 \mathrm{~g}$. This paper used standard pushover analysis to obtain probabilistic capacity curves. A modified adaptive technique was used to define the horizontal incremental load limit in order to automatically stop the pushover analysis during the run of a high quantity of structures, 1000 in this case. From the capacity spectra, simplified methods allow one to obtain DS thresholds and probabilistic fragility curves.

An interesting conclusion of this exercise is that uncertainties increase in the non-linear range. For the collapse DS, uncertainties in the fragility curves may be greater than $10 \%$. EDA and NLDA were used to obtain the ESD and its standard deviation as a function of PGA. Again, uncertainties increase with increasing PGA. This fact can be attributed to an increase in inelastic behaviour of the building. The EDA is a successful approach because it does not underestimate the actual displacement, but it can be too conservative in structures with higher ductility. Furthermore, the fact that both the ESD and the standard deviation are greater when calculated with the EDA than with NLDA verifies the conclusion that the EDA is conservative. In the NLDA, seismic action is mainly responsible for uncertainties in the spectral response, the influence of uncertainties in the mechanical properties of the building being less significant. However, as the DS increases, a sensitivity test shows a correla- tion between stiffness and spectral displacement. For $\mathrm{DS}_{3}$ and $\mathrm{DS}_{4}$, the spectral displacement decreases when stiffness increases, indicating that the probability of the corresponding damage state increases with stiffness. This result is important since $\mathrm{DS}_{3}$ and $\mathrm{DS}_{4}$ have a strong influence on calculation of the DI.

Finally, comparison of the DI as a function of PGA and the corresponding uncertainties shows that, for severe to collapse DSs, and for a confidence level of $95 \%$, uncertainties in the DI may be higher than 0.25 units or $42 \%$ of the DI. Thus, perhaps, the most important conclusion is that both static and dynamic structural analyses should be faced using probabilistic approaches.

\section{Acknowledgements}

This work was partially funded by the Geological Institute of Catalonia (IGC), the Spanish government and the European Commission with FEDER funds, through research projects CGL2008-00869/BTE， CGL2011-23621， CGL2011-29063, INTERREG POCTEFA 2007-2013/73/08, MOVE-FT7-ENV-

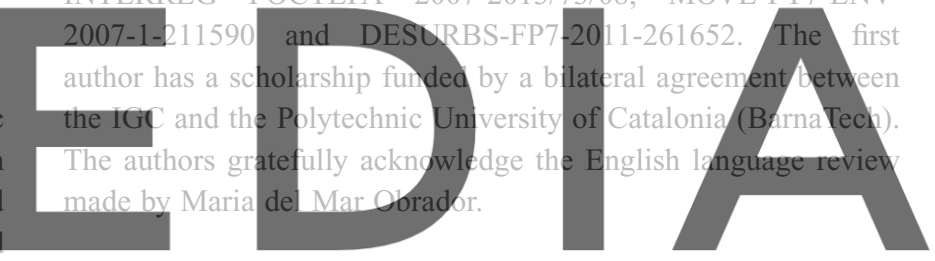

REFERENCES

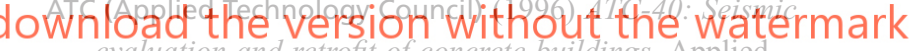 evaluation and retrofit of concrete buildings. Applied Technology Council, Redwood City, CA, USA.}

Barbat AH, Pujades LG, Lantada IN and IVloreno R (2008) Seismic damage evaluation in urban areas using the capacity spectrum method: application to Barcelona. Soil Dynamics and Earthquake Engineering 28(10): 851-865.

Barbat AH, Carreño ML, Pujades LG et al. (2010) Seismic vulnerability and risk evaluation methods for urban areas. A review with application to a pilot area. Structure and Infrastructure Engineering 6(1): 17-38.

Barbat AH, Carreño ML, Cardona OD and Marulanda MC (2011) Evaluación holística del riesgo sísmico en zonas urbanas. Revista Internacional de Métodos Numéricos para Cálculo y Diseño en Ingeniería 27(1): 3-27 (in Spanish).

Bommer J and Crowley H (2006) The influence of ground motion variability in earthquake loss modelling. Bulletin of Earthquake Engineering 4(3): 231-248.

Borzi B, Phino R and Crowley H (2008) Simplified pushover analysis for large-scale assessment of RC buildings. Engineering Structures 30(3): 804-820.

Carr AJ (2000) Ruaumoko - Inelastic Dynamic Analysis Program. University of Canterbury, Christchurch, New Zealand.

CEN (Comité Européen de Normalisation) (2004) EN 1998-1: 2004: Eurocode 8: Design of structures for earthquake resistance. Part 1: General rules, seismic actions and rules for building. CEN, Brussels, Belgium. 
Dolsek M (2009) Effects of uncertainties on seismic response parameters of reinforced concrete frames. In Safety Reliability and Risk of Structures, Infrastructures and Engineering Systems. (Furuta H, Frangopol D and Shinozuka M (eds)). CRC Press, Abingdon, UK, pp. 653-660.

Fragiadakis M and Vamvatsikos D (2010) Estimation of uncertain parameters using static pushover methods. In Safety Reliability and Risk of Structures, Infrastructures and Engineering Systems (Furuta H, Frangopol DM and Shinozuka M (eds)). CRC Press, Abingdon, UK.

Franchin P, Pinto P and Pathmanathan R (2010) Confidence factor? Journal of Earthquake Engineering 14(7): 989-1007.

Hancock J, Bommer J and Stafford PJ (2008) Numbers of scaled and matched accelerograms required for inelastic dynamic analyses. Earthquake Engineering and Structural Dynamics 37(14): 1585-1607.

Kim SP and Kuruma YC (2008) An alternative pushover analysis procedure to estimate seismic displacement demands. Engineering Structures 30(12): 3793-3807

Lantada N, Irizarry J, Barbat AH et al. (2008) Seismic hazard and

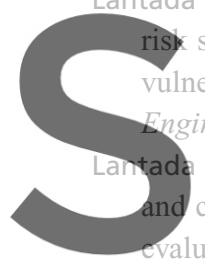
scenarios for Barcelona, Spai nerability index method. Bulletin ineering 8(2): 201-229. $N$, Pujades LG and Barbat A apacity spectrum based method
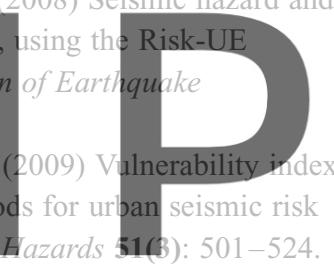

Mahaney JA, Paret TF, Kehoe BE and Freeman SA (1993) The

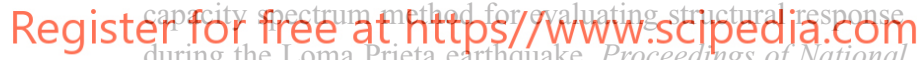
Earthquakes Conference, Memphis. TN. USA, pp. 501-510.

IViliutinovic ZV and Trendafiloski GS (2003) RiSK-UE project of the EC: an advanced approach to earthquake risk scenarios with applications to different European towns. WP04 Vulnerability of Current Buildings. Institute of Earthquake
Engineering and Engineering Seismology (IZIIS), Skopje, Republic of Macedonia.

Mwafy AM and Elnashai AS (2001) Static pushover versus dynamic collapse analysis of RC buildings. Engineering Structures 23(5): 407-424.

Otani S (1974) Inelastic analysis of RC frames structures. Journal of the Structural Division ASCE 100(7): 1433-1449.

Poursha M, Khoshnoudian F and Moghadam AS (2009) A consecutive modal pushover procedure for estimating the seismic demands of tall buildings. Engineering Structures 31(2): 591-599.

Pujades LG, Barbat AH, González-Drigo R, Avila J and

Lagomarsino S (2012) Seismic performance of a block of buildings representative of the typical construction in the Eixample district in Barcelona (Spain). Bulletin of Earthquake Engineering 10(1): 331-349.

Satyarno I (1999) Pushover Analysis for the Seismic Assessment of Reinforced Concrete Buildings. $\mathrm{PhD}$ thesis, University of Canterbury, Christchurch, New Zealand.

Vamvatsikos D and Cornell CA (2002) Incremental dynamic

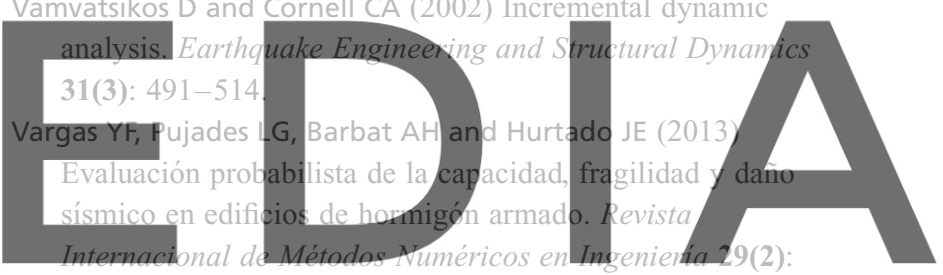

63-78 (in Spanish)

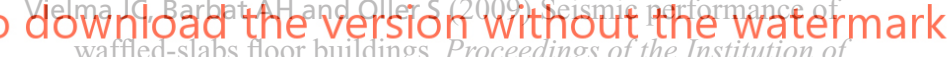 Civil Engineering - Structures and Buildings 162(3): 169-} 182.

Vielma JC, Barbat AH and Oller S (2010) Seismic safety of limited ductility buildings. Bulletin of Earthquake Engineering 8(1): 135-155.

\section{WHAT DO YOU THINK?}

To discuss this paper, please email up to 500 words to the editor at journals@ice.org.uk. Your contribution will be forwarded to the author(s) for a reply and, if considered appropriate by the editorial panel, will be published as a discussion in a future issue of the journal.

Proceedings journals rely entirely on contributions sent in by civil engineering professionals, academics and students. Papers should be 2000-5000 words long (briefing papers should be 1000-2000 words long), with adequate illustrations and references. You can submit your paper online via www.icevirtuallibrary.com/content/journals, where you will also find detailed author guidelines. 